\title{
O projeto educativo de José Vasconcelos no México pós- revolucionário: nacionalismo e modernidade
}

\author{
The educational and cultural project of José Vasconcelos in Posrevolucionary Mexico: \\ nationalism and modernity
}

Regina Crespo

Doutora em História Social Professora do Centro de Investigaciones sobre América Latina y el Caribe da Universidad Nacional Autónoma de México rcrespo@unam.mx

Resumo: Em junho de 1920, José Vasconcelos foi designado reitor da Universidade Nacional pelo presidente General Álvaro Obregón e, en outubro do ano seguinte, foi nomeado Ministro da Educação, posto que ocupou até julho de 1924. Durante este período, iniciou um ambicioso projeto cultural-educativo de âmbito nacional, que envolveu campanhas de alfabetização, edição e distribuição de livros, construção de bibliotecas e incentivo às artes. $\mathrm{O}$ presente trabalho se propõe analisar este projeto, especialmente no que se refere à sua proposta de educação indígena e rural, a fim de observar se e como contribuiu para, como pretendia Vasconcelos, construir um nacionalismo autoafirmativo e transformar o México num país moderno.

Palavras-chave: José Vasconcelos, Nacionalismo, projeto cultural-educativo

\begin{abstract}
In July 1920, José Vasconcelos was appointed dean of the Universidad Nacional by president General Álvaro Obregón and, in October 1921, he was in charge of the Ministry of Education, position he occupied until July 1924. During this period, Vasconcelos started an ambitious educational and cultural plan that included literacy campaigns, printing and distribution of books all around the country, building of libraries and support for the arts. The aim of this essay is to analyze this project, specially the educational plan for the indigenous and rural populations, to see if it contributed, as Vasconcelos pretended, to the construcction of an autoaffirmative nationalism and if it could help to transform Mexico in a modern country.
\end{abstract}

Keywords: José Vasconcelos, Nationalism, cultural and educational projects. 


\section{Introdução}

A Revolução Mexicana, iniciada em novembro de 1910, trouxe à luz as contradições de uma sociedade desigual e dividida. A cidade do México, capital de um país politicamente centralizado, espelhou e de certa maneira potenciou tais contradições. Durante o conflito foi invadida e ocupada várias vezes e, nela, os distintos grupos políticos que lutavam pelo poder debateram e decidiram os rumos políticos, econômicos e sociais do país, num processo sinuoso, em que os projetos se sucediam à medida em que mudavam os líderes e os grupos que representavam. Não é tarefa fácil estudar e entender o contexto cultural e educativo do país durante e depois de praticamente dez anos de uma verdadeira guerra civil. O movimento das tropas e facções opostas invadindo várias cidades e gerando êxodos e reocupações, num fluxo contínuo de destruição e tentativas de reconstrução, deixou um país devastado e uma população exausta.

Foi justamente na capital mexicana, iniciada a década de 1920, que se gestou um plano educativo e cultural inovador para um país que lentamente se recompunha. Muitas das ações que se geraram então não puderam transcender os limites geográficos e ideológicos da capital. No entanto, várias delas conquistaram uma maior amplitude e visibilidade. Algumas continuam vigentes ainda hoje, outras permanecem como referência importante para o México atual.

É possível afirmar que a educação e a cultura foram ferramentas fundamentais no processo de estabilização que o general Álvaro Obregón procurou implementar no México, ao assumir a presidência do país, em janeiro de 1920. Obregón manteve os slogans de estímulo ao trabalho que seu antecessor, o general Venustiano Carranza, havia criado com o intuito de reconstruir o país. Também manteve --e aprofundou--- a estratégia de aproximação diplomática com os países latino-americanos, inaugurada por Carranza para contrabalançar a terrível propaganda que o governo dos Estados Unidos fazia do México junto a eles. No entanto, favorecido por um momento político mais estável, Obregón pode avançar muito mais, anunciando um projeto de regeneração social e reafirmação nacional, cujo maior artífice foi, sem sombra de dúvidas, José Vasconcelos. O projeto educativo e cultural que Vasconcelos elaborou e começou a desenvolver durante os quatro anos em que permaneceu, primeiro à frente da Universidade Nacional e, depois, da Secretaria de Educação Pública, indicou caminhos rumo a um México 
econômica e socialmente mais moderno e apontou a um nacionalismo autoafirmativo que marcaria todas as políticas educativas e culturais posteriores.

\section{0 grande projeto cultural-educativo}

José Vasconcelos, advogado famoso, membro do prestigioso "Ateneu da Juventude", ${ }^{1}$ antigo componente do partido Antireelecionista de Francisco Madero e fiel defensor deste que foi primeiro herói e mártir da revolução Mexicana, foi convidado a ocupar a reitoria da Universidade Nacional, logo que Obregón assumiu a presidência. A ideia de colocar à frente da reitoria um intelectual com visibilidade na mídia e ampla circulação social representou uma estratégia sagaz do general presidente, que teria consequências importantes para o seu próprio governo. Vasconcelos utilizou sua posição de reitor como plataforma para lançar um plano muito mais ambicioso: a refundação da Secretaria de Educação Pública. ${ }^{2}$ Esta havia sido suprimida durante a presidência do general Venustiano Carranza, em obediência à Constituição de 1917, que retirara da educação o seu caráter federal. Em todo o país as escolas passaram a depender das prefeituras, que não tinham condições financeiras de mantê-las. Na capital do país, as escolas ficaram sob a responsabilidade de um departamento administrativo, o Departamento Geral de Educação (VÁZQUEZ, 2000: 151).

Ao assumir a reitoria da Universidade, Vasconcelos deixou claro seu objetivo de fazer com que a instituição trabalhasse pelo México e, para isso, que se aproximasse da população, abandonando a torre de marfim típica dos artistas e intelectuais (FELL, 1989: 18-19). Sua primeira ação foi conclamar professores, estudantes, donas de casa e os setores médios de modo geral a envolver-se numa campanha massiva de alfabetização. Com amplo apoio dos jornais, a campanha se iniciou com enorme repercussão e foi uma ferramenta importante para visibilizar e legitimar a refundação da Secretaria de Educação Pública. Vasconcelos elaborou um Projeto de Lei, que implicaria modificar a própria Constituição recentemente promulgada. Ele mesmo se encarregou de defendê-lo junto aos políticos e à opinião pública, conseguindo que o decreto de criação da Secretaria fosse

\footnotetext{
${ }^{1} \mathrm{O}$ "Ateneu da Juventude" foi um grupo hoje consagrado pela história cultural mexicana, que reuniu jovens filósofos, poetas, pintores e políticos, chegando a contar com 69 integrantes. Entre seus membros mais famosos, estavam Vasconcelos, Alfonso Reyes, Antonio Caso e Pedro Henríquez Ureña. Com suas discussões sobre Platão, Schopenhauer, Bergson e Kant, os ateneístas representaram uma ruptura no corpo até então monolítico da cultura porfiriana. Não conformavam um grupo ideologicamente homogêneo, mas ainda assim tiveram uma participação essencial na política e na vida cultural mexicana

${ }^{2}$ As secretarias mexicanas são equivalentes aos ministérios brasileiros.
} 
assinado por Obregón em 3 de outubro de 1920. No dia 12 do mesmo mês, Obregón nomeou Vasconcelos Secretário, função que exerceu até 27 de julho de $1924 .^{3}$

À frente da Secretaria, com o apoio de alguns de seus antigos colegas do "Ateneu de la Juventude" e de um grupo de jovens colaboradores, que posteriormente chegariam a ser importantes funcionários e políticos, Vasconcelos pode colocar em prática o projeto que elaborou e defendeu. Seu plano educativo e cultural era não só de regeneração social como de reafirmação nacional. O temor que o projeto despertou no início, ao suscitar uma confusão entre federalização e centralização (tema nevrálgico num país politicamente centralizado como o México) desapareceu quando professores de vários estados se manifestaram observando que a federalização da educação levaria à criação de diretivas gerais controladas por um Conselho Federal composto por representantes de todos os estados do país. O resultado do projeto seria o respeito à autonomia e à soberania das instituições educativas locais, com a conquista de unidade técnica, similaridade de programas de estudo e equivalência de aprendizagem em toda a República. Como diriam os professores do estado de Veracruz, se alcançaria então “el fin más elevado en materia educativa: la formación del alma mexicana" (FELL, 1989: 65, itálicas no original).

O projeto de Vasconcelos - assumidamente inspirado nas ações culturais de Anatoly Lunacharsky à frente da Secretaria de Educação da União Soviética durante a década anterior (VASCONCELOS, 1993b: 19) - abrangia todas as áreas da educação, da pré-escola à educação indígena, das bibliotecas à edição de livros e revistas, do ensino técnico ao artístico. Como recordaria Vasconcelos em suas memórias, de acordo com o seu projeto, a Secretaria de Educação Pública se dividia em três departamentos: escolas, bibliotecas e belas artes. O departamento de escolas englobaria todo o ensino, teórico e prático. O departamento especial de bibliotecas (uma necessidade permanente para o país, que só o Estado poderia cumprir) funcionaria como complemento da escola para a criança

\footnotetext{
3 A nebulosa e intempestiva saída de Vasconcelos da SEP esteve marcada por uma longa série de circunstâncias. Obregón precisava que os Estados Unidos reconhecessem o seu governo para poder retomar o crescimento do país. O governo estadunidense, por sua vez, condicionou este reconhecimento à firma de acordos (conhecidos como Tratados de Bucarelli) em que, entre outras coisas, se garantiam os direitos de propriedade dos cidadãos dos Estados Unidos radicados no México e também das companhias petroleiras. Os tratados eram visivelmente lesivos para o país e Calles, quando assumiu a presidência, os cancelou. Em suas memórias, Vasconcelos recorda que um deputado, Field Jurado, se negou a assiná-los e foi assasinado na própria câmara. Este episódio o levou a demitir-se do governo. A demissão não foi aceita na primeira vez, mas na segunda, sim. Vasconcelos decidiu, então, concorrer ao governo de seu estado natal, Oaxaca, e perdeu. $\mathrm{O}$ ex-ministro recordaria que sua atuação à frente da SEP chamava a atenção e gerava ciúmes entre os demais membros do ministério e o próprio Obregón (VASCONCELOS, 1993: 116, 129, 143), o que estimulou o seu afastamento do governo. Também lembraria a significativa e gritante diminuição do orçamento destinado à sua pasta pelo próprio Obregón.
} 
e o adulto. O departamento de belas artes reuniria o ensino de canto, de desenho e de ginástica nas escolas, e também, nas palavras do próprio Vasconcelos, os institutos de “cultura artística superior” Academia de Belas Artes, Museu Nacional e conservatórios. Os três departamentos operariam juntos a partir da escola primária. As ciências seriam ensinadas pela escola propriamente dita, as artes e ginástica por especialistas ou pelos próprios professores, e as bibliotecas permaneceriam a serviço de todos, em seus diversos departamentos, infantil, técnico, literário, etc. ( $c f$. VASCONCELOS, 1993b: 18)

Além desses três departamentos, Vasconcelos acabou acrescentando ao seu projeto um departamento auxiliar de ensino indígena (Departamento de Cultura Indígena), responsável pela incorporação dessa vasta população aos programas educativos do país, a cargo de professores que deveriam imitar os missionários católicos da colônia, em sua missão evangelizadora. A postura de Vasconcelos com relação aos indígenas mudaria radicalmente ao longo do tempo, em direção a um conservadorismo e um eurocentrismo notórios. No entanto, quando esteve à frente da Universidade Nacional e da SEP, o ministro manteve uma posição muito mais flexível e tolerante. Como veremos, a associação entre o âmbito rural e as comunidades indígenas e a compreensão da existência das necessidades específicas dessas comunidades fariam com que Vasconcelos contemplasse, em seu projeto, uma atenção especial ao ensino de práticas associadas à melhoria em suas condições de vida, sem cair no que o ministro considerava a política de segregacionismo adotada pelos Estados Unidos com relação às suas populações indígenas.

En José Vasconcelos: los años del Águila (1920-1925), Claude Fell estudou o período mais importante da atividade pública de Vasconcelos. ${ }^{4}$ A obra de Fell, de consulta obrigatória para todos os estudiosos da ação político-cultural de Vasconcelos, tem como subtítulo "Educación, cultura e iberoamericanismo en el México postrevolucionario". Este trabalho, indubitavelmente o mais completo realizado sobre o tema, evidencia, na própria relação entre o título e o subtítulo, o protagonismo de Vasconcelos nos âmbitos educativo e cultural dos anos 1920. Pensar na cultura e na educação desse período é, como indica Fell, pensar em Vasconcelos. E pensar em Vasconcelos requer considerar a adição

\footnotetext{
${ }^{4}$ O período de 1920 a 1925 consistiu no que Vasconcelos recordaria como a época em que se dedicou à obra e à ação social. "Breves años - diria o autor - en que fue mi pasión la multitud, sus dolores y sus potencialidades (VASCONCELOS, 1993b: 10). Durante esses cinco anos, além de atuar como reitor, criar e comandar a SEP e perder as eleições para governar Oaxaca, Vasconcelos escreveu alguns livros e se dedicou ao jornalismo. Fundou e dirigiu a revista La Antorcha, primeiro no México e depois na Europa, para onde acabou viajando numa espécie de autoexílio. Em 1925, em Paris, saiu a primeira edição de sua obra mais famosa, La raza cósmica.
} 
de um terceiro elemento, o iberoamericanismo, que Fell percebe como um diferencial importante da contribuição do mexicano. Pode-se dizer que Vasconcelos concebeu o iberoamericanismo como uma espécie de nacionalismo continental, que contemplava todos os povos hispano e luso parlantes do continente, e funcionava como um patriotismo de defesa diante da perene ameaça dos vizinhos do norte, da América anglo-saxã. Entre outras influências que se podem perceber na obra e no pensamento de Vasconcelos, não resta dúvida acerca da forte presença do arielismo de Rodó. Seu efeito sobre o projeto foi notório.

Recordemos que as escolas, bibliotecas e as artes foram concebidas por Vasconcelos como um conjunto coeso de ferramentas e instituições, organizado a partir do Estado para chegar à população de todo o país com o objetivo de integrá-la a um projeto nacional. Vasconcelos objetivou, desde o princípio, consolidar uma nação que não renegasse o seu passado indígena, mas que adotasse o caminho ocidental de matriz hispânica. Afinal de contas, para ele, fora a partir da Conquista e da criação da "Nova Espanha" que o domínio espanhol e católico lançou as bases para o surgimento do México moderno. A oposição ao pragmatismo protestante, tão cara a Rodó, também aparece em Vasconcelos e faz parte do substrato ideológico, estético e político da integração realizada a partir da cultura.

A formação humanista está no âmago do projeto de Vasconcelos. A incorporação social através da alfabetização, necessária à retomada do crescimento econômico e à recuperação da normalidade política em um país conturbado, desigual, com uma maioria de analfabetos, foi a ação inaugural de um projeto de matiz cristão e, em certo sentido, voluntarista. O voluntarismo se reflete justamente na campanha massiva com que Vasconcelos preparou a recriação do ministério de educação, conclamando os mexicanos educados a contribuir na alfabetização da população urbana e rural, mestiça e indígena. Mais do que defender o utilitarismo protestante, Vasconcelos advogou pela construção de um espírito de comunidade inexistente ou, quando muito, pouco relevante entre seus conterrâneos. Apostou na ação redentora da classe média, que ainda era incipiente, mas que poderia, dada a sua preparação intelectual, agir como vanguarda na transformação social que o Estado, como mecenas, financiaria e dirigiria.

A formação humanista também se deixa ver no projeto editorial grandiloquente levado adiante pelo ministro, principalmente nos primeiros dois anos de sua gestão, quando os recursos aprovados por Obregón foram extraordinariamente altos, chegando a $15 \%$ do orçamento geral da federação (ARCE GURZA, 1985: 158). Esta situação 
favorável lhe permitiu investir na produção de revistas, boletins e livros, distribuídos gratuitamente em todo o país e concebidos para faixas específicas de leitores, de professores e estudantes a pessoas comuns. ${ }^{5} \mathrm{O}$ acesso geral aos livros, distribuídos ou organizados em bibliotecas públicas, contribuiria para a continuação do trabalho iniciado nas campanhas voluntárias de alfabetização e ajudaria a elevar o nível intelectual da população.

Finalmente, a formação humanista também aparece no plano artístico concebido por Vasconcelos, que oferecia à maioria da população a oportunidade de acesso ao conhecimento e ao prazer estético associados às chamadas belas artes e o compartilhamento de um conjunto de tradições, que Vasconcelos definia como nacional e popular. O ministro orientou seu projeto em várias direções. Com a perspectiva de realizar a educação artística do povo, o estímulo às artes plásticas foi potente. A ação mais transcendente, que consagraria mundialmente a pintura mexicana, foi a criação do movimento muralista. A ideia de Vasconcelos, ao oferecer aos pintores as paredes de grandes edifícios públicos, era transformar os espaços de circulação social em lugares para a a contemplação estética, até então privilégio das elites ou, no máximo, limitada aos museus. A iniciativa se uniu ao estímulo às escolas de pintura ao ar livre, com a colaboração de pintores que se dispuseram a trabalhar como professores, e à valorização das artes decorativas populares. O pintor Best Maugard recebeu o encargo de normalizar o ensino de desenho e artes manuais nas escolas primárias do Distrito Federal. Para isso elaborou um método, do qual se produziram 15 mil cópias, utilizadas em 248 escolas primárias, 2 normais e 4 técnicas. Segundo um Boletín de la SEP, aprenderam com ele 71.157 alunos. A ideia, em 1923, era formar 2000 professores especializados no método para difundi-lo em todo o país, o que não foi possível, dada a diminuição do orçamento da SEP (FELL, 1989: 435, 444).

Festivais culturais, bailes e exibições de cinema e de teatro ao ar livre também foram atividades estimuladas pela SEP. Alguns deles chegaram a contar com o apoio de empresários e donos de cinemas e teatros. Entre fevereiro e junho de 1922, realizaram-se 97 festivais culturais no Distrito Federal e 30 nos municípios vizinhos (DE LOS REYES,

\footnotetext{
${ }^{5}$ É importante fazer alguns comentários com relação à produção editorial da SEP. Entre os vários veículos que se editaram durante a administração de Vasconcelos, ganharam importância os Boletines de la SEP e a revista $E l$ Maestro. Enquanto os boletins veiculavam principalmente temas especificamente relacionados à educação e às atividades da SEP, a revista El Maestro pretendia ser um instrumento de divulgação em grande escala de temas culturais, morais, científicos e artísticos (além, é claro, de funcionar como um eficiente "cartão de visitas" do ministério).
} 
1993: 138-141). Artistas locais eram convidados a participar, nas escolas as crianças eram preparadas para apresentar canções e danças e se aproveitava a ocasião para oferecer conferências sobre temas de interesse comum e culturais como "a origem e a civilização da raça asteca". O estímulo à música, aos espetáculos coletivos e ao esporte culminaram na construção do polêmico Estádio Nacional, cuja inauguração foi a última realização de Vasconcelos como ministro.

Durante o curto período em que Vasconcelos permaneceu como ministro, o movimento artístico, importantíssimo na capital, alcançou algumas cidades, principalmente as maiores, mas não chegou a todo o país. No entanto, não se pode negar que funcionou como uma espécie de "detonador" de um movimento cultural de massas, que se consolidou ao longo dos anos, sob outros presidentes e ministros.

Talvez o principal resultado de tal movimento cultural tenha sido a já mencionada construção de um nacionalismo autoafirmativo. Porém, se consideramos o caráter plurilinguístico, multiétnico y multicultural da sociedade mexicana, é necessário perguntar como Vasconcelos concebia a construção desse nacionalismo e como pensava em relacioná-lo com a necessária modernização econômica e social do país. Em primeiro lugar, se recordamos que, no tripé sobre o qual o projeto vasconcelista se apoiava (escolas, bibliotecas, artes), o livro possuía o papel protagonista, coadjuvado pela escola e pelas artes, como poderíamos pensar na construção de uma nação unitária, se uma parte significativa da população nem sequer pensava e se comunicava em espanhol? Em segundo lugar, como poderíamos pensar em uma cultura nacional, se parte da população, diferenciada étnica e regionalmente, cultivava valores e costumes de origem pré-colonial e compartilhava cosmogonias próprias (já modificadas pelo catolicismo dos antigos missionários, mas ainda assim distintas das tradições ocidentais e especificamente espanholas)? Finalmente, como pensar um projeto de modernização econômica, política e cultural que incorporasse uma população arraigada no campo e distanciada dos valores e interesses da sociedade urbana moderna que começava a predominar no México e que o Estado pós-revolucionário pretendia expandir?

Vasconcelos assumia, às vezes implicitamente e em outros momentos de maneira explícita, a existência de uma inevitável dicotomia entre dois grupos que simbolizavam dois Méxicos distintos compartilhando o mesmo território. Em seu discurso político e nas manifestações em defesa do projeto educativo-cultural para o país, havia sempre um "nós", que reunia basicamente professores, estudantes, intelectuais e artistas, e um "eles", que continha toda a população não escolarizada, de caráter mestiço ou indígena. 
Vasconcelos sabia que os membros desse enorme setor social ainda não haviam conquistado o status de cidadãos. Os mestiços e indígenas espalhados pelo México, distantes dos avanços e das possibilidades de desenvolvimento social e pessoal proporcionados pela sociedade moderna e urbana, não possuíam um saber que lhes permitisse viver nessa nova sociedade e os libertasse do que Vasconcelos considerava preconceitos e atavismos. Para conquistar tudo isso, deveriam passar por um processo de "regeneração", que só poderia dar-se via o trabalho educativo. Desta maneira se explica a aposta do ministro na função do livro em espanhol como instrumento de cultura e se entende, também, sua crença no papel missionário dos professores.

Apesar de propugnar a eliminação ou, pelo menos, a diminuição dos privilégios que separavam as elites econômicas, sociais e culturais da grande maioria da população do país, Vasconcelos nunca deixou de legitimar a existência desses dois grupos, "nós" e “eles”. A constatação da separação abissal entre ambos constituiria o primeiro passo deste intelectual e político, como ministro da educação, rumo à tentativa de construir um processo de incorporação das massas a uma cultura nacional e aos valores democráticos. Entretanto, a retórica cristã que utilizava para defender a missão regeneradora dos intelectuais, professores e artistas, nunca foi forte o bastante para questionar a existência das diferenças hierárquicas, estruturais no tecido social. Ao contrário, Vasconcelos muitas vezes as justificou com argumentos tênues, como o da existência de uma "jerarquía natural, que nos hace diferentes en capacidad y en necesidades y aptitudes" (VASCONCELOS, 1993a: 929). A legitimação de tais diferenças contribuiu para fazer também com que o ministro conclamasse a elite cultural a "educar" o povo, colocando exclusivamente em suas mãos o poder de decidir sobre o que seria ou não interessante ensinar-lhe. Ora, para Vasconcelos, as prerrogativas de liderança, mando e decisão sempre estariam com o primeiro grupo de atores e jamais com o segundo, sempre à espera, por sua própria natureza, de uma palavra guia, de uma direção.

Nesse sentido, a revista El Maestro, que Vasconcelos começou a editar quando ainda era reitor da Universidade Nacional, constitui um exemplo interessante para observar como entendia a missão da elite cultural no país. Ao explicar a importância da revista dentro do projeto educativo da SEP, Vasconcelos afirmaria: "la verdadera luz no tiene precio, y luz será lo que procuraremos difundir, ofreciéndola, dándola aún a los que no la pidan". Ao considerar o saber como uma característica da elite, da qual se colocava como grande líder, Vasconcelos justificava o seu próprio e evidente paternalismo: "nós" os iluminaremos, ainda que não o peçam. Não por acaso, Vasconcelos abriu o primeiro 
número da revista El Maestro, com um chamado cordial a todos os professores do país, aos que incluía numa significativa primeira pessoa do plural, afirmando: "escribiremos para los muchos [...] con el propósito constante de elevarlos, y no nos preguntaremos qué es lo que quieren las multitudes, sino qué es lo que más les conviene, para que ellas mismas encuentren el camino de su redención" (VASCONCELOS, 1921: 6-7).

Segundo os objetivos do plano educativo-cultural de Vasconcelos, o México plurilinguístico, multiétnico y multicultural deveria ser redimido, nacionalmente unificado e ideologicamente direcionado rumo ao desenvolvimento econômico, à estabilidade política e à harmonia social. A relativa estabilidade do período pósrevolucionário abria espaço para ações transformadoras e até certo ponto generosas como as que o ministro procuraria adotar ao criar o Departamento de Cultura Indígena.

\section{Ensino indígena, escolas rurais}

Passados os primeiros efeitos da grande campanha de alfabetização voluntária fomentada por Vasconcelos, evidenciaram-se os seus limites. Também se tornou patente a necessidade de um trabalho contínuo e sistemático da SEP, não só no âmbito urbano, como principalmente junto às comunidades rurais e de maioria indígena, que não haviam sido nem sequer atingidas por aquela campanha. $\mathrm{O}$ ministro decidiu estipular uma série de regras para os professores missionários diretamente relacionados com as comunidades indígenas, forçando-os a entender a população com que tinham que trabalhar. Em uma circular da SEP, publicada em 1923, Vasconcelos recomendava aos professores "penetrar la mentalidad de sus educandos, no sólo para influir sobre ellos con mayor eficacia, sino para también descubrir la porción de verdad que sin duda se conserva en los usos y conocimientos de los indígenas" (FELL, 1989: 243).

Esta abertura à mentalidade e aos costumes das populações autóctones e a busca simultânea de influir sobre elas, oferecendo-lhes os "avanços da civilização", remete a uma preocupação integracionista que se podia encontrar no já mencionado trabalho evangelizador dos missionários (Vasco de Quiroga e Bartolomé de las Casas eram insistentemente recordados por Vasconcelos). No entanto, também se associa aos projetos de integração social ligados à assimilação dos povos indígenas à sociedade nacional. Alguns anos antes, educadores como Abraham Castellanos e Gregorio Torres Quintero se preocuparam em elaborar uma educação especificamente destinada às populações indígenas. O primeiro respeitando e cultivando as suas especificidades culturais e 
linguísticas, o segundo, acreditando na inevitabilidade do desaparecimento das línguas indígenas, a partir da necessária educação no espanhol, como língua nacional. Segundo Fell, a educação indígena contemplada por Vasconcelos em seu projeto educativo não deixava de ser uma readaptação das "escolas rudimentares", que haviam sido instituídas por um decreto federal em junho de 1911 e que foram arduamente defendidas por Torres Quintero (FELL, 1989: 204-205). Mas, se Vasconcelos teve a estes educadores como antecessores e interlocutores indiretos, também coincidiu em ação e concepção com antropólogos como Manuel Gamio, que em muitos sentidos antecedeu Vasconcelos na criação de políticas públicas especificamente destinadas à integração nacional deste importante setor social.

Cabe fazer um parêntese para recordar este autor que sempre lutou pelo conhecimento das populações indígenas, institucionalizando a antropologia e os estudos de campo para poder levar a cabo o seu propósito de "forjar a pátria". Não por acaso, Forjando patria foi o título do livro mais conhecido de Gamio, publicado em 1916, no qual o autor propunha a integração das populações indígenas ao corpo da nação, e colocava em cheque os preceitos positivistas e evolucionistas ainda dominantes para explicar e justificar o lugar marginal e subalterno que tais populações ainda ocupavam no México. Como antropólogo formado na escola culturalista de Boas, Gamio sempre se posicionou de maneira contrária à visão homogeneizante dos indígenas, dominante no país e ponto de partida para as poucas políticas públicas especificamente destinadas a este importante grupo social. O próprio Vasconcelos, apesar das recomendações aos professores missionários, pretendeu, desde o princípio, "castelhanizar" e "redimir" os índios, considerando-os, como acabamos de ver, uma população carente de iniciativa e de ações redentoras. Gamio pretendia primeiramente conhecer as populações indígenas a partir de um ponto de vista científico, levando em conta dados estatísticos, análises qualitativas, ambientais e históricas.

O antropólogo dividia a população mexicana em três grupos: o primeiro, de indivíduos de raça e sangue "indígena", histórica e socialmente representados por servos e oprimidos; o segundo, de indivíduos de sangue misto, que o autor também definia como "classe média", a única, capaz de criação intelectual e em cujo seio nasceram sempre os movimentos de rebeldía contra o terceiro grupo, composto etnicamente por individuos descendentes de estrangeiros e socialmente definidos como la aristocracia -rica mas desprovida de cultura. O mapa socioétnico de Gamio se assemelhava muito ao concebido por Vasconcelos e também para ele a redenção do México não poderia gerar-se nem pelo 
primeiro e nem pelo terceiro grupo. Gamio acreditava na ação transformadora das camadas médias e, como Vasconcelos, também aproximava o conceito de raça ao de classe social para defini-las (CRESPO, 2005: 116). No entanto, é preciso reconhecer que Gamio não soube ou talvez não pode encontrar um espaço, dentro de seu modelo de classificação, para refletir sobre o lugar social dos enormes setores da população mestiça que não se inseriam nas camadas sociais médias urbanas e que se mantinham muito mais próximos, em termos de marginalidade de acesso à riqueza, aos indígenas e ao mundo rural.

Em 1916, sob a presidência de Carranza, Gamio criou o Departamento de Antropologia (o primeiro que se fundou na América Latina), dentro da Secretaria de Agricultura. Nele, dirigiu uma das primeiras pesquisas interdisciplinares do mundo, tomando como campo de trabalho o Vale de Teotihuacán. Gamio e sua equipe realizaram uma enorme contribuição tanto no campo antropológico como no arqueológico, além de buscar e propor políticas de melhoramento das condições de existência das populações indígenas da zona, dentro de seu meio físico e social e em relação com o entorno. ${ }^{6}$ Além de estimular o conhecimento das características raciais, manifestações culturais, situação econômica e social das populações regionais para apoiar a elaboração de políticas públicas, o Departamento de Antropologia deveria encarregar-se da preparação de "un acercamiento racial, de la fusión cultural, de la unificación lingüística y del equilibrio e económico de dichas agrupaciones, las que sólo así formarán una nacionalidad coherente y definida y una verdadera patria" (GAMIO, 1985: 38). Como podemos ver, no projeto de Gamio, a antropologia e a ação social deveriam caminhar juntas. O papel do departamento de Antropologia deveria ser ativo e abrangente, com critérios ideológicos claros e sólido conhecimento científico.

Durante todo o período em que Vasconcelos dirigia a SEP, Gamio esteve no Departamento de Antropologia. O fato de que o departamento fundado por Gamio fizesse

\footnotetext{
${ }^{6}$ Durante dois anos Gamio dirigiu uma equipe com cerca de 40 antropólogos, sociólogos, linguístas, historiadores, arquitetos e artistas que se dedicaram a conhecer a zona a partir de sua própria disciplina e em diálogo e colaboração entre os demais membros do projeto. O resultado foi uma obra em três extensos volumes, intitulada La población del Valle de Teotihuacan, publicados pela SEP em 1922. O fato de que a SEP tenha publicado esse longo estudo comprova a importância, a extensão e os alcances do programa editorial criado por Vasconcelos. Recordemos que o ministro editou vários livros clássicos da literatura e da cultura ocidentais, em enormes tiragens. Esta iniciativa recebeu a crítica irada de muitos jornalistas e intelectuais, que não entendiam o porquê de publicar e distribuir Ilíadas e Odisséias num país de analfabetos e com um grande contingente de população indígena. Ao lado dessas publicações. porém, Vasconcelos abriu espaço para a difusão de obras sobre o México e escritas por mexicanos. Os responsáveis pelo programa editorial da SEP souberam perceber a importância de publicar este trabalho pioneiro, que contribuiria para o conhecimento profundo das populações indígenas do país.
} 
parte da Secretaria de Agricultura denota a associação automática das populações indígenas com o mundo rural e agrícola. Por outro lado, no programa de Vasconcelos, a educação indígena também se associava, quase que por antonomasia, às escolas rurais. $\mathrm{O}$ Departamento de Antropologia e a SEP jamais agiram de forma coordenada, apesar de que muitas vezes pareciam inspirar-se reciprocamente. Vasconcelos e Gamio nunca trabalharam juntos, o que não deixa de indicar não só a falta de organicidade do governo durante o período, como a existência de uma provável competição política e ideológica entre ambas esferas e seus dois coordenadores.

É interessante notar que os estudos que Gamio coordenou sobre o vale de Teotihuacán apontavam aos problemas oriundos da concentração das terras em poucas mãos, da falta de empregos e do baixo nível educativo da população em geral e indígena em particular. Gamio e sua equipe buscaram influenciar a Comissão Nacional Agrária para que se outorgassem propriedades aos camponeses sem terra e conseguiram que se construísse uma estrada e uma estação de trens a fim de acabar com o isolamento da região e para que se estimulasse o turismo na zona das pirâmides, como fonte de renda para a população local (CRESPO, 2005: 117). Gamio planejou expandir o tipo de trabalho que dirigiu em Teotihuacán a outras regiões do país, mas os alcances dessa experiência interdesciplinar pontual ainda tardariam muito em transformar-se em uma opção a ser considerada dentro da política nacional relacionada às populações indígenas.

Quanto a Vasconcelos, não podemos esquecer que o espectro de ação do ministério que dirigia, a SEP, era muito maior que o do Departamento de Antropologia, coordenado por Gamio, o qual se inseria no organograma de uma pasta cujo tema primordial era a agricultura e não a questão indígena. $\mathrm{O}$ alcance das políticas levadas a cabo pela SEP no âmbito da educação indígena e rural foi, portanto, muito mais amplo. Para isso, Vasconcelos contou com o apoio fundamental de Enrique Corona, coordenador do Departamento de Cultura Indígena. A exemplo de Gamio e do próprio Vasconcelos, Corona sabia que a solução das causas da pobreza entre a população indígena partia da repartição de terras, mas sabia também que esta questão evidentemente não dependia exclusivamente das decisões e ações da Secretaria de Educação Pública. Nesse sentido se entende o trabalho de natureza mais lenta e tenaz que Corona propunha para a área. Corona foi o responsável pela criação e organização das chamadas "Casas do Povo", que deveriam centralizar a ação educativa nas comunidades em que a maioria da população (mais de 60\% ) fosse comprovadamente indígena e onde ainda não existisse nenhuma instituição educativa, pública ou privada (FELL, 1989: 240-241). A Casa do Povo deveria 
ser um centro de comunicação e interação entre a comunidade local, os professores missionários e jovens professores normalistas originários da própria comunidade, formados para apoiá-la. Deveria funcionar como ponte entre a comunidade e a SEP, por intermédio do Departamento de Cultura Indígena.

Durante os anos de 1923 e 1924, houve uma notória expansão no número de Casas. Tal expansão foi acompanhada, porém, da eclosão de vários conflitos com a igreja católica, que as via como uma ameaça à sua profunda e até então inconteste hegemonia. Também foi comprometida pela ausência de fundos públicos para a sua manutenção, já que as Casas requeriam a formação de professores locais e, consequentemente, a fundação, em número suficiente, de escolas rurais regionais, com um currículo adaptado às suas especificidades. A ideia de Corona de que as Casas do Povo estimulassem as comunidades indígenas a conquistar autonomia agrícola e também econômica, com o desenvolvimento e a venda de sua produção artesanal implicava a manutenção de uma estrutura não só comunitária, mas também profissional, o que requeriria mais apoio da SEP. Os professores misionários deveriam ter menos saber livresco e mais conhecimentos práticos, inclusive de labores agrícolas, o que tampouco era simples de conseguir. Mas, apesar de todas as dificuldades, limitações de orçamento e inclusive do descompasso entre a ação da SEP e outras secretarias, como a própria Secretaria de Agricultura, a iniciativa de Vasconcelos e especialmente o trabalho de Corona foram marcantes para direcionar as políticas públicas no âmbito da educação indígena e rural e tiveram continuidade, inclusive depois de sua saída da SEP.

Em seu contato com as comunidades indígenas, podemos afirmar que Gamio conseguiu ultrapassar a perspectiva mais voluntarista e condescendente, implícita no projeto educativo de Vasconcelos. Como antropólogo, sugeria uma relação de mão dupla entre educadores e educandos, contando com que os primeiros tivessem não somente boa vontade, mas um certo grau de relativismo cultural para poder entrar, sem preconceitos, em um universo cultural diferente do seu. A máxima "indianizemo-nos", associada ao pensamento e à ação de Gamio materializava sua preocupação em não "europeizar" os indígenas de uma maneira avassaladora, drástica e imediata (proposta implícita no plano “castelhanizador” de Vasconcelos e no de Torres Quintero, que o antecedeu). De qualquer forma, se sua tática era suave e, por assim dizer "sedutora", não por isso era menos incisiva. Diria o autor: 'indianicémonos' nosotros un tanto, para presentarle [al indígena], ya diluida con la suya nuestra civilización, que entonces no encontrará exótica, cruel, amarga e incomprensible (GAMIO, 1982: 96). A pergunta inevitável aqui é se a 
"indianização" dos professores, antropólogos e de qualquer outro profissional que se aproximasse das comunidades indígenas não acabaria por representar simplesmente o estabelecimento de uma ponte mais curta para a sua compulsória integração. A separação que observamos em Vasconcelos, entre um "nós", detentor das ferramentas do saber e da comunicação e um "eles", desprovido dos mecanismos que o saber letrado representa se repetiria em Gamio.

Gamio considerava que indígenas, mestiços e brancos viviam em uma espécie de “desajuste temporal”, mas isso não o levava a defender una homogeneização cultural e linguística que representasse o exterminio das culturas autóctones. Para ele, por exemplo, o idioma espanhol deveria funcionar como uma espécie de língua franca entre os vários grupos indígenas e entre estes e o resto del país, mas isso não deveria significar o fim de las línguas autóctones, que poderiam ser preservadas. No entando, sua preocupação em estabelecer iniciativas para o "melhoramento" das condições de existência das populações indígenas iria inevitavelmente conduzi-las a uma gradativa "ocidentalização". Em tal contexto, a alfabetização em espanhol, propugnada como uma ferramenta para combater o isolamento das comunidades indígenas, cedo ou tarde representaria o fim de suas línguas maternas, como un passo inelutável para uma unificação cultural ou, se preferimos, para a "nacionalização" dos habitantes do país (CRESPO, 2005: 118-119).

Vasconcelos, por sua vez, objetivava explícita e imediatamente tal unificação. Não podemos negar que sua luta contra as desigualdades deixava pouco espaço para o exercício das diferenças. É importante recordar que o autor possuía uma concepção cíclica da história da humanidade, a qual plasmaria detalhadamente em seu ensayo La raza cósmica, publicado, como já vimos, em 1925, depois de sua saída da SEP. Sua perspectiva etapista o levou a concluir que o tempo dos indígenas ja havía terminado. Assim, para que pudessem desenvolver-se não lhes restava outro caminho que se integrar à cultura moderna (VASCONCELOS, 1992: 25). A alfabetização massiva em espanhol constituía, sem nenhum subterfúgio, o ponto de partida fundamental para o grande processo de unificação cultural e também política do México, unida à inserção profissional desses grandes setores sociais marginalizados no país, via o aperfeiçoamento de labores associados ao seu lugar de origem, o mundo rural. De acordo com o regulamento da SEP (que fora publicado no segundo Boletín de la SEP, de 1922), correspondia ao professor missionário estabelecer-se e circular por uma região delimitada, tratando de dirigir e supervisionar o trabalho dos professores residentes (ex-alunos ou pessoas já alfabetizadas dispostas a ensinar). Deveria organizar programas de ensino apropriados à população 
indígena, estimular, além do ensino da língua espanhola e de rudimentos de aritmética, a aquisição de conhecimentos práticos e úteis, de noções de higiene e, também, de arte, história e civismo. Facilidade, simplicidade e virtude seriam os instrumentos suficientes, segundo o próprio documento, para "ganarse a los indígenas", e conseguir "levantar el espíritu de estos hombres simples e ignorantes, infundirles entusiasmo y fe en su porvenir y en el futuro de la Patria” (CRESPO, 2005: 126).

Como podemos ver, para Vasconcelos a integração das populações indígenas ao corpo da nação implicava o aperfeiçoamento de práticas associadas ao seu entorno imediato, mas também pressupunha a difusão de um ideário capaz de soldar uma plataforma identitária comum. Nesse sentido, também ele estava "forjando patria" e, assim, a perspectiva integracionista de seu plano educativo e a de Gamio teriam mais semelhanças que diferenças. No entanto, enquanto o caminho percorrido pelo antropólogo o levaria a abraçar o indigenismo, o percurso de Vasconcelos faria com que o negasse. Em busca de um México unificado, na defesa de um país moderno, mais orgulhoso dos resultados advindos de sua colonização espanhola que da exuberância de seu passado indígena, Vasconcelos foi paulatinamente deixando a visão simpática e generosa com relação às populações autóctones, e passou a propugnar a mestiçagem cultural e racial como única saída para o futuro do país.

\section{Influências e legado do projeto vasconcelista}

Se queremos realizar um balanço do projeto vasconcelista temos que considerar que ele se dividiu em várias vertentes de ação, integradas de maneira sistêmica. $\mathrm{O}$ ministro, como grande gestor de um Estado que deveria agir como mecenas, procurou desenvolver o seu projeto, cuidando para que se mantivessem seus propósitos e se alcançassem os seus objetivos. Buscou também, em benefício da dinâmica das ações, propiciar um relativo grau de autonomia para cada um de seus setores, zelando pelo seu funcionamento de maneira integrada com os demais. Dada a abrangência dos temas a tratar e resolver numa pasta tão ampla como a de educação pública, Vasconcelos optou por garantir alguma independência de gestão a muitos de seus colaboradores. O tema da autonomia, apesar do centralismo das ações de Vasconcelos, esteve muito presente em sua administração e gerou uma transformação das esferas decisórias da máquina do 
Estado, no sentido de obter mais agilidade e destreza. ${ }^{7}$ Talvez não seja exagero afirmar que, nesse sentido, o projeto vasconcelista foi, realmente, um passo importante em direção à modernização do aparato governamental mexicano.

Não cabe nenhuma dúvida acerca da enorme influência que o projeto educativo e cultural de Vasconcelos exerceu sobre o México que surgiu depois da Revolução. É possível notar também como muito do que propôs norteou as políticas educativas e culturais durante décadas. Finalmente, como comentamos na introdução deste breve trabalho, não é exagero afirmar que algumas de suas ideias continuam vigentes ainda hoje e outras permanecem como referência importante para o México atual.

O orgulho nacionalista, tão marcante nas décadas de 1920 e 1930, resultou em um trabalho paulatino de difusão de pautas artísticas, culturais e históricas organizado e dirigido pela SEP, a partir do projeto vasconcelista. A preocupação inicial de Vasconcelos de buscar universalizar entre todos os mexicanos a possibilidade de acesso à cultura letrada, em especial a que se relacionava com as origens espanholas da cultura mexicana, permeou as políticas educativas nacionais, muito embora nem sempre na direção que o antigo ministro houvesse gostado. Assim, enquanto o presidente Obregón apoiou o projeto e seu inquestionável humanismo, seu sucessor, o antigo professor primário, também originário do norte do país, Plutarco Elías Calles, preferiu orientar a educação nacional em direção a um ensino mais profissionalizante e eficientista, associando crescimento econômico e progresso. Sua perspectiva era de que os camponeses deveriam saber plantar e os operários, produzir com novas e melhores técnicas. A grande preocupação de Calles era fazer com que o México saísse finalmente do caos econômico onde estava desde a Revolução e a educação tinha que servir a estes propósitos (ARCE GURZA, 1985: 146).

Os políticos que se fizeram responsáveis pela direção do país a partir do período pós-revolucionário tiveram que adotar políticas que levassem o México a retomar o crescimento econômico (por isso a questão do aprimoramento e da eficientização do trabalho era primordial). Mas tiveram, também, que buscar a criação de uma plataforma identitária comum que fizesse com que setores sociais dissímiles se sentissem parte de um Estado-nacional ainda desestabilizado política e economicamente, cheio de

\footnotetext{
${ }^{7}$ Um caso interessante de exercício de autonomia entre os colaboradores de Vasconcelos foi o dos pintores muralistas. Contratados por Vasconcelos para pintar as paredes de algumas instituições de arte e educação, trabalharam com uma independência temática quase completa, chegando inclusive a contradizer muitas das concepções estéticas e ideológicas do ministro.
} 
contradições e desigualdades étnicas, culturais e de classe. Esta segunda tarefa foi, de certa maneira, "cumprida" por Calles em 1929. As eleições presidenciais, para as quais José Vasconcelos retornou ao México e das quais saiu derrotado, representaram a ocasião ideal para que Calles difundisse a ideia de uma harmonia social possível, a partir da criação de um partido de Estado, o Partido Nacional Revolucionário (o futuro PRI), cuja ideia de unidade plasmou sobre uma imagem grandiloquente e simultaneamente sedutora para uma sociedade conservadora e cristã como a mexicana: o partido da grande família revolucionária, onde todos os mexicanos teriam um lugar.

Vasconcelos pautou sua campanha na ideia de que o México poderia ter um filósofo na presidência e de que os caudilhos militares inevitavelmente voltariam aos quartéis. Fracassou em seu projeto. As eleições foram fraudulentas e houve mortes e violência entre os seguidores do ex-ministro. No entanto, o projeto de um partido único e a ideia de um México unificado se impuseram paulatinamente no imaginário nacional, recorrendo, inclusive, a muito do impulso do próprio Vasconcelos em valorizar o país e a fazer com que os mexicanos se sentissem orgulhosos de a ele pertencer. $\mathrm{O}$ seu multifacetado projeto cultural-educativo abriu uma série de vetas para as políticas educativas e culturais e para a consolidação daquele nacionalismo autoafirmativo com o qual gerações de mexicanos seriam socializadas na escola e nas instituições culturais, principalmente nos museus de história nacional e arqueologia, espalhados por todo o país.

Podemos dizer que, a partir da saída de Vasconcelos da SEP, os ministros que o sucederam tiveram direta ou indiretamente que dialogar ou discutir com o plano que ele deixou. Em termos gerais, a questão específica da educação rural e indígena continuou sendo pautada pelos preceitos integracionistas, seja na linha missionária cristã, inaugurada por Vasconcelos, seja na linha da política indigenista defendida por Gamio e daquela levada a cabo no âmbito da própria SEP, já sob as ordens de Puig Cassauranc, na presidência de Calles, pelo subsecretário Moisés Sáenz.

Um último parêntese é necessário para alguns breves comentários sobre Sáenz. Oriundo do norte do país (como Calles e Obregón), Sáenz decidiu abraçar a causa indígena quando ainda era um jovem professor normalista, ao perceber como a ausência de igualdade entre os mexicanos fazia dessa população em particular um evidente objeto da discriminação. Como funcionário da SEP, viajou por todo o país fundando escolas rurais nos moldes do aprendizado produtivo, que tanto agradava ao General Calles, 
associados aos princípios da escola ativa de Dewey, de quem foi discípulo. ${ }^{8}$ A exemplo de Vasconcelos e Gamio, Sáenz também pretendia a integração do México, mas reconhecia e valorizava a enorme diversidade regional e cultural do país e não queria que ela fosse apagada (RICO, 2015). Em seu livro México íntegro, publicado em 1939, quando já não trabalhava mais na SEP, Moisés Sáenz afirmaria, em evidente referência a Vasconcelos, que "es más fácil uniformar y emparejar, que integrar armónicamente" (apud RICCO, 2015). Neste livro, o político e pedagogo defendia a construção de uma "patria grande", resultado de um pluralismo cultural, regulado por um sistema econômico justo e eficaz. ${ }^{9}$

Hoje, Moisés Sáenz está praticamente esquecido. O grande indigenista lutou para oferecer alternativas educativas e culturais mais democráticas e igualitárias e expandiu os horizontes para a discussão e criação de políticas públicas destinadas às populações indígenas. Aa ideias e a ação de Sáenz servem para ilustrar, também, como o conteúdo do projeto educativo-cultural de Vasconcelos pautou e de certa maneira continua pautando a discussão acadêmica e política no México.

Podemos dizer que as contribuições teóricas e metodológicas implícitas na elaboração e aplicação de políticas públicas especificamente relacionadas ao campo educativo e, particularmente, à população indígena, de autores como Vasconcelos, Corona, Gamio e Sáenz foram inovadoras e progressistas quando surgiram. Porém, se ainda funcionam como norteadoras da discussão nesse campo, mostram um evidente anacronismo e esgotamento. Díaz Polanco (2003:37) reconhece que, durante o século $\mathrm{XX}$, a política indigenista mexicana se baseou nas propostas do chamado

\footnotetext{
${ }^{8}$ Entre as várias iniciativas que se tomaram na SEP, durante a gestão de Puig Cassauranc, podemos citar a criação do Departamento de Missões Culturais, um esforço importante para organizar e expandir os alcances desta que foi uma criação de Vasconcelos. As "Missões Culturais" eram enviadas ao interior da república e normalmente eram integradas por um chefe da missão, um professor de pequenos ofícios, um professor de música, outro de educação física, uma professora de economia doméstica, um médico para o ensino de práticas de higiene e vacinação e um professor especialista em práticas de ensino. Com a criação do Departamento, Puig Cassauranc pode expandir o número das missões e o seu alcance territorial. Durante sua gestão, o Departamento de Cultura Indígena se transformou em Departamento de Escolas Rurais (a ênfase da SEP se concentrou no ensino rural, partindo do pressuposto da forte presença indígena nas comunidades rurais). E, em 1925, fundou-se a Casa do Estudante Indígena, uma tentativa fracassada de Sáenz em formar professores indígenas, levando-os a experimentar a vida urbana. Significativamente, muitos já não quiseram regressar ao seus lugares de origem, o que abriu espaço (e continua abrindo) para uma série de reflexões sobre as relações concretas entre o universo rural e o urbano e sobre os reais interesses, desejos e projetos dos indígenas.

9 Recordemos que Moisés Sáenz foi designado como o primeiro diretor do Instituto Indigenista Interamericano, criado no México em 1940, durante o Primeiro Congreso Indigenista Interamericano, em Pátzcuaro, evento que Sáenz ajudou a organizar. A morte o alcançou antes de que assumisse o posto e, em 1941, Gamio o sucedeu. O Instituto funcionou como uma plataforma a partir da qual se estimulou a criação de institutos nacionais indigenistas ao longo de toda a América Latina.
} 
“integracionismo". Para o antropólogo mexicano, existem integracionismos extremos e outros mais elaborados, mas no final todos acabam chegando ao mesmo lugar: tudo o que na cultura indígena seja obstáculo para a conformação de uma cultura nacional (unilateralmente definida pelo Estado), deverá ser eliminado (de manera sutil -convertido en folclore, por exemplo- ou de forma direta). Díaz Polanco afirma que uma característica do integracionismo é que quer conseguir o seu objetivo "sem dor e sem conflitos" (2003:41). É justamente aqui que as políticas e projetos educativos se encaixam de maneira perfeita (IGLESIAS, 2015:63) e legitimam, até hoje, as práticas de assimilação uniforme.

No México atual, com o domínio das práticas neoliberais no campo educativo, a padronização é cada vez maior e mais estimulada pelo governo do país. A sobrevivência das escolas normais rurais, que surgiram com Vasconcelos, cresceram com Calles e se consolidaram com Cárdenas, tem sido cada vez mais difícil. ${ }^{10}$ A tragédia do desaparecimento de 43 normalistas da Escola Normal Rural de Ayotzinapa em 2014, que comocionou o mundo e revoltou a sociedade mexicana, lança um alerta sobre a ruptura radical e cada vez mais profunda entre as demandas educativas da população e as exigências do mercado. Apesar dos esforços do Estado em homogeneizar a formação de docentes e normatizar o seu trabalho em todo o país, as Escolas Normais Rurais ainda resistem, permitindo que estudantes de origem camponês, de baixíssimos recursos econômicos se formem e possam trabalhar nas zonas rurais, atuando em consonância com o que se espera acadêmica, política e socialmente de um professor nessas regiões. Num país em que as taxas de analfabetismo permanecem altas, a distância entre o mundo urbano e mundo rural continua profunda e a discriminação étnica não foi superada, as escolas normais rurais ainda cumprem com as expectativas e necessidades das populações que atendem.

Não deixa de ser curioso observar que, ao mesmo tempo em que o Estado mexicano abandona ou penaliza um projeto inclusivo como o das escolas normais rurais, apoie institucionalmente a criação de uma rede de Universidades Interculturais (UI) especificamente destinadas às comunidades indígenas. Apesar de longa, vale a pena ler a descrição, em estilo bastante institucional, da natureza, origem e propósitos das UI mexicanas:

\footnotetext{
${ }^{10} \mathrm{Um}$ dos ataques mais fortes às normais rurais foi impetrado pelo presidente Díaz Ordaz, em 1969, quem mandou fechar 15 das 29 então existentes no país, justificando sua decisão com a acusação que estas escolas eram "ninhos de comunistas" (PADILLA, 2009: 92).
} 
En México, las Universidades Interculturales (UI) se crearon como una forma de atención a la comunidad indígena como sujeto de intervención. En el Programa Nacional de Desarrollo para Pueblos Indígenas 2001-2006 se estableció como línea estratégica la de transformar las instituciones, reasignar funciones, adecuar su desempeño y crear espacios institucionales que hicieran más efectiva la atención a los pueblos indígenas. Las Universidades Interculturales son instituciones que se ubican en regiones densamente indígenas. Como su nombre lo indica, no son exclusivamente para indígenas, pero sí preferentemente para indígenas por el lugar donde están ubicadas[...] De ahí que el Gobierno Federal emitiera un acuerdo para la creación de la Coordinación General de Educación Intercultural Bilingüe (CGEIB) como parte de la Secretaria de Educación Pública (en enero de 2001), cuyo propósito es asegurar que la educación intercultural bilingüe responda con calidad a las necesidades de educación de la población indígena. (NAVARRETE CAZALE \& ALCÁNTARA SANTUARIO, 2015: 154)

Ao ler a passagem acima, por um lado é inevitável observar a presença de alguns elementos que lembram a educação segregacionista que Vasconcelos associava aos protestantes yanques e que tanto combatia. Por outro lado, em pleno século XXI, observamos em seu conteúdo ao menos algumas reminiscências dos propósitos das missões culturais e das escolas rurais da segunda década do século XX. Haveria que pensar sobre a ação concreta das UIs e seus resultados. Que portas o mercado laboral abrirá aos profissionais egressados de uma Universidade que se apresenta como intercultural, mas que está destinada especialmente à população indígena?

Um movimento diferente, que se desenvolve em uma nova direção, é a experiência de educação autônoma levada a cabo nas zonas zapatistas, nos chamados "caracóis". Ainda que analisar a educação zapatista ultrapasse os objetivos deste trabalho, é interessante saber que está estruturada de uma maneira completamente distinta à da educação padronizada e nacionalizada oferecida e controlada pelo Estado. Segundo Cecilia Iglesias (2015:143), no território ocupado pelos zapatistas, as escolas são conduzidas pelos Municipios Autónomos Rebeldes Zapatistas (MAREZ), em coordenação com as assembléias, autoridades comunitárias, comitês de educação e, especialmente, com os educadores. Não são funcionários do governo municipal, estadual ou federal que deliberam e decidem sobre a organização escolar e os conteúdos e métodos 
pedagógicos, mas sim as próprias famílias dos estudantes em cada comunidade, que além disso, elegem os educadores com os quais contarão, designando-os, em uma forma mais horizontalizada, "promotores de educação". A partir da breve descrição de algumas das características dessa experiência pedagógica, podemos notar que o movimento zapatista em Chiapas trouxe para o debate político a necessidade de transformar a relação entre os povos indígenas e a sociedade mexicana em seu conjunto (REYNOSO, 2013).

De maneira distinta, as Universidades Interculturais e os os Caracóis Zapatistas colocam tanto o indigenismo como as políticas integracionistas em xeque. A imagem precursora de Vasconcelos e seu projeto educativo continua funcionando como um referente com o qual dialogar ou como etapa a ser suplantada.

\section{Fontes}

VASCONCELOS, José (1921). Un llamado cordial. El Maestro. México, SEP, v. I, n. 1, abr.-sep., pp. 6-7.

(1992). La raza cósmica. Misión de la raza iberoamericana, 16a. ed., México, Espasa-Calpe, 1992.

(1993a). Memorias: La tormenta. Vol. 1. México: Fondo de Cultura Económica, Vol. 1, pp. 453-955.

(1993b). Memorias: El desastre. Vol. 2. México: Fondo de Cultura Económica, pp. $9-598$.

\section{Referências bibliográficas}

ARCE GURZA, Francisco (1985). En busca de una educación revolucionaria. In: VÁZQUEZ, Josefina et alii, Ensayos sobre historia de la educación en México. 2 ed. México: Colegio de México, pp. 145-187.

CRESPO, Regina (2005). Itineraris intelectuals: Vasconceslo, Lobato y sus proyectos para la nación. UNAM/CCyDEL

DE LOS REYES, Aurelio (1993). Cine y sociedad en México 1896-1930. Bajo el cielo de México. vol. II (1920-1924). México: UNAM.

DÍAZ POLANCO, Héctor (2003). Indigenismo y diversidad cultural. México: Universidad de la Ciudad de México.

FELL, Claude (1989). José Vasconcelos: Los años del águila. Educación, cultura e iberoamericanismo en el México postrevolucionario, México, UNAM.

GAMIO, Manuel (1985) Antología, COMAS, Juan (estudio preliminar, selección y notas), 2.a ed., México, UNAM.

GAMIO, Manuel, (1982) Forjando patria, 3 ed. México: Porrúa.

IGLESIAS, Maria Cecilia (2015). Interculturalidad y descolonización: las experiencias educativas en los caracoles zapatistas y la Universidad de los Pueblos del Sur (UNISUR): una lectura en clave latinoamericana. México: UNAM, Tesis de Maestría. 
NAVARRETE CAZALE, Zaira \& ALCÁNTARA SANTUARIO, Armando (2015). Universidades interculturales e indígenas en México desafíos académicos e institucionales. Revista Lusófona de Educação, n. 31, pp. 145-160. Disponível em: <http://www.redalyc.org/html/349/34944227009/>. Acesso: 19 jul. 2016.

PADILLA, Tanalis (2009). Las normales rurales: historia y proyecto de nación. El Cotidiano. México, UAM, n. 154, mar.-abr., pp. 85-93.

REYNOSO, Jaime Irving (2013). Manuel Gamio y las bases de la política indigenista en México. Andamios, México, vol. 10, n. 22, pp. 333-355. Disponível em: <http://www.scielo.org.mx/scielo.php?script=sci_arttext\&pid=S187000632013000200017\&lng=es\&nrm=iso>. Acesso: 21 jul. 2016.

RICCO, Sergio (2015). Moisés Sáenz y su paternidad negada en la historia de la antropología latinoamericana. Pacarina del Sur. año 6, n. 23, abr-jun. Disponível em: <http://www.pacarinadelsur.com/home/huellas-y-voces/1138-moises-saenz-ysu-paternidad-negada-en-la-historia-de-la-antropologia-latinoamericana>. Acesso: 13 jun. 2016.

VÁZQUEZ, Josefina (2000) [1970]. En busca de una educación revolucionaria. In: VÁZQUEZ, Josefina, Nacionalismo y educación en México. México: El Colegio de México, Primera reimpresión, pp. 151-224.

Artigo recebido em 30 de setembro de 2016.

Aprovado em 01 de outubro de 2016. 